\title{
Mandatory Child Restraint Laws: Impact on Childhood Injuries Due to Traffic Crashes
}

\author{
Alexander C. Wagenaar
}

\begin{abstract}
Research has indicated that laws requiring use of restraint devices for young children traveling in automobiles have had significant effects in increasing restraint use and reducing crash-related childhood injuries. This study examined dimensions along which the effectiveness of Michigan's April 1982 mandatory child restraint law varied. All children involved in motor vehicle crashes in Michigan from January 1978 through December 1982 were analyzed using multivariate intervention analysis methods. Research revealed that the effectiveness of the law in reducing childhood injuries was primarily due to reductions in less severe injuries occurring in crashed vehicles experiencing low to moderate levels of damage. Furthermore, the mechanism for the law's effects was not simply an increase in restraint use. In addition, the number of children riding in the more dangerous front-seat and cargo-area positions apparently decreased following implementation of the law, with children increasingly riding in the safer rear-seat position.
\end{abstract}

Injuries and deaths due to motor vehicle crashes are a major public health problem in the State of Michigan as elsewhere. Injuries, most of which are associated with motor vehicles, are the leading cause of death for those in the first half of life (Verway, 1982), as well as a frequent cause of disabling injury. In 1982 alone, 1,417 Michigan residents died and 130,061 were injured in motor vehicle crashes. Costs associated with health care and lost productivity are a significant burden, both in

Alexander C. Wagenaar, $\mathrm{PhD}$, is on the senior research staff of The University of Michigan Transportation Research Institute, Ann Arbor, MI 48109-2150.

Funds for this study were provided by the Michigan Office of Highway Safety Planning and the National Highway Traffic Safety Administration. Findings and conclusions, however, are solely those of the author. terms of direct costs paid by the state and costs paid by citizens through numerous other mechanisms (Andary, Flora, Huelke, \& O'Day, 1981). The pain and suffering caused by traffic crashes is incalculable. Not included in many assessments of automobile crash costs are such secondary effects as marital and family instability, psychological stress, and alcohol and drug abuse in families where a member has been killed or seriously injured in a crash (Kaufman \& Bilge, 1982; Rubin, 1982).

Currently available technology, in the form of occupant restraint systems, can substantially reduce the risk of injury and death associated with motor vehicle travel. The effectiveness of properly used restraint systems in reducing injury among crash-involved au- 
tomobile occupants is beyond dispute. Of major concern to health and safety officials is the large proportion of the motoring public that does not regularly use existing occupant restraint systems. A recent survey of Michigan residents revealed an average self-reported belt use rate of approximately $28 \%$ (McGinley Marketing Research, 1982; O’Day \& Filkins, 1983), but self-reports typically overestimate actual use. Estimates of observed (rather than self-reported) belt use vary from study to study, depending primarily on the sample design. The most recent observational study of occupant restraint use in Michigan indicated an overall use rate of $13.8 \%$ (O'Day \& Wolfe, 1984).

Increasing the proportion of the motoring public that is protected by occupant restraint devices is a major priority among safety officials, public health professionals, and others. There are three main approaches to increasing restraint use. One traditional approach relies on public information and education campaigns to persuade individuals to use the seat belt restraint systems already available. The best programs have been able to increase knowledge concerning restraints and have occasionally changed restraint attitudes. Few programs, however, have achieved significant increases in restraint use-particularly when evaluated for long-term effects.

A second major approach to increasing the proportion of restraint-using motorists is through the installation of passive or automatic restraint systems in new vehicles. Universal installation of passive restraint systems is likely to significantly reduce injury and death due to motor vehicle crashes (Warner, 1983). A detailed discussion of the debate surrounding mandating passive restraints is beyond the scope of this paper. Nevertheless, a few issues should be noted. First, if installation of passive restraints in new vehicles were mandated, it would take 10 or more years before the vehicle population completely turned over and passive restraints were available in most vehicles in use. Second, airbag passive restraints are most effective in reducing injury caused by frontal-impact crashes. They are less effective in other crash configurations and thus should be viewed as an important supplement to, not a replacement for, existing seat belt systems. Third, it is difficult for the states to require installation of passive restraint systems on all vehicles driven in their states. Passive restraint installation is best required on all new automobiles by the federal government, resulting in a substantial reduction in per-vehicle cost due to economies of scale. In short, while compulsory installation of passive restraint systems is a fruitful means of reducing crash-related deaths and injuries, it will not eliminate the need to increase use of existing restraint systems, and it is a less convenient focus for policy attention at the state level.

The third major approach to increasing the proportion of motor vehicle occupants that are adequately restrained is compulsory use of existing seat belts. Numerous countries have implemented mandatory adult seat belt use laws. The laws have frequently been associated with increased seat belt use and decreased crash casualty rates. While only one state (New York, effective December 1984) has passed a general adult mandatory belt use law, 49 states have implemented compulsory restraint use for young children. Making belt use compulsory for motor vehicle occupants of all ages is currently under debate in several states.

The pattern of policy changes in most western countries has been the opposite of that in the United States. Many countries in the 1970 s implemented mandatory adult restraint use laws that explicitly excluded young children. After the benefits of adult use laws were observed, several countries then revised their mandatory occupant-restraint policy to include young children. In contrast, in recent years most states in the U.S. have implemented mandatory restraint laws for young children, but only New York has passed similar legislation applying to adult vehicle occupants. In this country it is apparently politically more acceptable to require young children to be restrained than adults, because children are unable to decide for themselves to use restraints and take the requisite action. Moreover, some advocate child restraint laws as a first step in building public support for mandatory restraint use for occupants of all ages. There are some early signs that mandatory restraint policies for young children are gradually being expanded to other populations. New York, for example, began mandating re- 
straint use for young children in April 1982. In March 1983, a regulatory change made restraint use compulsory for those driving under a learner's permit (New York State Department of Motor Vehicles, 1983). In April 1984, legislation was enacted to extend the mandatory child restraint law to all vehicle occupants below the age of 18; and, since December 1984, all front seat occupants and all children 10 and under, regardless of seat location, have been required to use seat belts.

One state for which the effectiveness of a mandatory child restraint law has been carefully evaluated is Michigan. Michigan's law, which took effect April 1, 1982, requires that children age $0-3$ be restrained in an approved child seat when traveling in an automobile. Children age 1-3 may be restrained with an adult lap belt provided they are riding in the rear seat. Detailed time-series analyses of traffic crashes from 1978 through 1982 revealed that, beginning in the first month with the law, restraint use among crash-involved young children age 1-3 tripled (from 12 to $36 \%$ ). ${ }^{1}$ Restraint use among infants under age 1 could not be accurately measured because of small sample sizes. Injuries among infants under age 1 declined $50 \%$, however, and injuries among toddlers age 1-3 declined at least $17 \%$ (Wagenaar, 1984). These figues represent the net effect attributable to the child restraint law, controlling for the effects of long-term trends and cycles. Similar increases in restraint use and reductions in injuries were not found for occupants of other ages. Based on these results, an estimated 458 childhood injuries per year are prevented by the compulsory restraint use law in Michigan.

The purpose of the study reported here was to clarify the nature of the injury-reducing effects of Michigan's child restraint law. Does the law simply increase restraint use, which in turn leads to a reduction in injuries, or does it have more complex effects? Are there other changes in behavior as a result of the law that contribute to the reduction in injuries? Is the

'This is a conservative estimate of restraint use based on Michigan residents injured in motor vehicle crashes. Direct observation studies indicate that restraint use among the general population of young children on the road is over $50 \%$. law more effective in reducing injuries among certain types of motorists? This study was designed as an initial examination of dimensions along which effectiveness of child restraint laws vary.

\section{METHOD}

Information on occupants involved in motor vehicle crashes was obtained from the Michigan State Police. Records were available for all traffic crashes that occurred in the State of Michigan and that were reported to local or state police agencies. Detailed information on age, restraint use, and other factors was available for all injured occupants. The only information available for uninjured occupants, however, was whether or not they were using a restraint at the time of the crash. Information on age, sex, and other characteristics of uninjured occupants (other than drivers) is not recorded by police officers investigating traffic crashes in Michigan.

The complete data files contained records on about 750,000 crash-involved occupants per year. Files for the years 1978 through 1982 were used to calculate the number of crash-involved occupants per month for numerous subgroups of interest. Cases included in all the time-series variables were filtered to include only passenger cars and light trucks, thus limiting the data analyzed to the target population of recent restraint use efforts. Restraint use by occupants of buses and motor homes, for example, is a separate issue; similarly, passengers on farm equipment, construction equipment, or motorcycles are not subject to the mandatory restraint use laws. Michigan's child restraint law applies only to Michigan residents; therefore, the time-series were filtered to include only occupants of vehicles with a driver possessing a Michigan driver's license. Nonresidents also were less exposed to the major public information and education efforts that accompanied implementation of the law. This focus on the target group increased the accuracy of the assessment of the effects of recent restraint use efforts.

As with any available source of data, police records on restraint use and injuries among children involved in motor vehicle crashes are not perfect. First, the measure of 
restraint use is based on police officers' judgement concerning use in serious crashes and on a combination of officer judgement and selfreporting in less serious crashes. Motorists with young children might be more likely to incorrectly report an unrestrained child as restrained when restraint use is legally required. Thus, a change in reported restraint use after the law took effect may be a combination of a change in actual use and a change in reporting.

The findings reported below rely primarily on children recorded as injured in crashes. Although about a third of all crash-related injuries are not recorded by police (Barancik, Chatterjee, Greese, Michengi, \& Fife, 1983), this is not a significant problem for studies of the effect of child restraint laws. A consistent undercount of the number of injuries does not prevent an estimate of the change in injury frequency after passage of a restraint law. A more serious question is whether reporting of injuries changed when the law took effect. Such a coincidental change in reporting would make it more difficult to determine the true impact of the law on the incidence of injuries. It is possible that drivers involved in crashes are less likely to report injuries to children after a law mandating child restraint use is implemented. Because the penalty for failure to restrain a child in Michigan is a maximum of $\$ 10$, however, and because citations for failure to restrain a child are infrequent, there is little incentive for a crash-involved driver to lie about injuries to children in the vehicle.

The number of crash-involved motor vehicle occupants per month was examined for an extended time period for each of the categories included in the research design. Long series of observations were required to assess the degree to which injury frequencies in 1982 (after child restraints became mandatory) were different from the level expected, given regular patterns over the previous 4-year period.

The main objective of the analyses was to estimate shifts in each time series associated with the legal intervention in April 1982. To estimate such shifts beginning the first month after the law took effect, long-term trends and seasonal cycles must first be controlled. The Box-Jenkins and Box-Tiao (Box \& Jen- kins, 1976; Box \& Tiao, 1975) intervention analysis methods were used to accomplish this. The methods combine baseline modeling techniques with intervention impact models. The time-series (Auto-Regressive Integrated Moving Average) models are developed iteratively, repeatedly going through cycles of specifying a model, estimating it, and evaluating its adequacy. The Box-Jenkins approach is a versatile time-series modeling strategy that can model a wide variety of trend, seasonal, and other recurring patterns.

This analytic strategy involves explaining as much of the variance in occupant injuries as possible based on the past history of restraint use or injuries, before attributing any of the variance to another variable such as passage of a compulsory restraint use law. This intervention analysis approach was particularly appropriate for the present study, since the objective was to identify significant shifts in injury rates associated with the child restraint law, independent of observed regularities in the history of each variable. Without these methods, incorrect conclusions might be made. For example, a decrease in injuries might be fully attributed to the law, when in fact it is entirely consistent with a preexisting multiyear downward trend in injuries. In short, controlling for baseline trends and cycles with time-series models produces more accurate estimates of the effects of restraint-use legislation. ${ }^{2}$

All of the time-series models estimated included parameters for the child restraint public information and education (PI\&E) program implemented that began January 1982 (Office of Highway Safety Planning, 1981). With only one exception, parameters estimating the effects of the PI\&E efforts alone (i.e., January-March 1982) were not significant. The following discussion of the effects of the mandatory child restraint law (beginning April 1982) actually refers to the effects of the law and of simultaneous PI\&E efforts.

\footnotetext{
${ }^{2}$ Major findings are summarized here. Detailed results of the analyses are available in Wagenaar, A. C. Restraint Usage Among Crash-involved Motor Vehicle Occupants, February 1984, available from the National Technical Information Service, Report No. PB84173715 .
} 


\section{RESULTS}

The first dimension along which effectiveness of the child restraint law was found to vary is injury severity. Injured children were divided into two groups according to the severity of their injuries. The first group consisted of moderately injured children, including those recorded as having a "possible" or "nonincapacitating" injury. The second group consisted of severely injured children, including fatalities and those recorded as having sustained an "incapacitating" injury. After controlling for the downward trend from 1979 through 1981, the number of children experiencing moderate injuries dropped an estimated $22 \%$ when the child restraint law took effect (Figure 1). In contrast, severe injuries did not decrease significantly, after accounting for the moderate negative trend over the baseline period (Figure 2). If one disregards the baseline trend, an estimated $24 \%$ reduction in severe injuries is associated with the child restraint law. In short, it appears that the child restraint law had its main effect in reducing moderate injuries and was less effective in reducing severe injuries and death.

While a small proportion of crashes are unsurvivable even with restraints, the larger effect of the law on moderate injuries is not due to lower effectiveness of restraints in more severe crashes. The larger effect of the child restraint law in reducing moderate injuries is most likely due to higher rates of restraint use among those involved in less severe crashes. Belt use varied from $15.4 \%$ among crashinvolved occupants with no injury to only $3.8 \%$ among those fatally injured (Table 1). It appears that those at greatest risk of severe injury are those least likely to change their (non)restraint-using behavior as a result of mandating legislation. This proposition was explicitly tested by time-series analyses of childhood injuries categorized by crash severity, as measured by extent of vehicle damage. Vehicle damage provides a measure of the seriousness of a crash independent of injuries sustained.

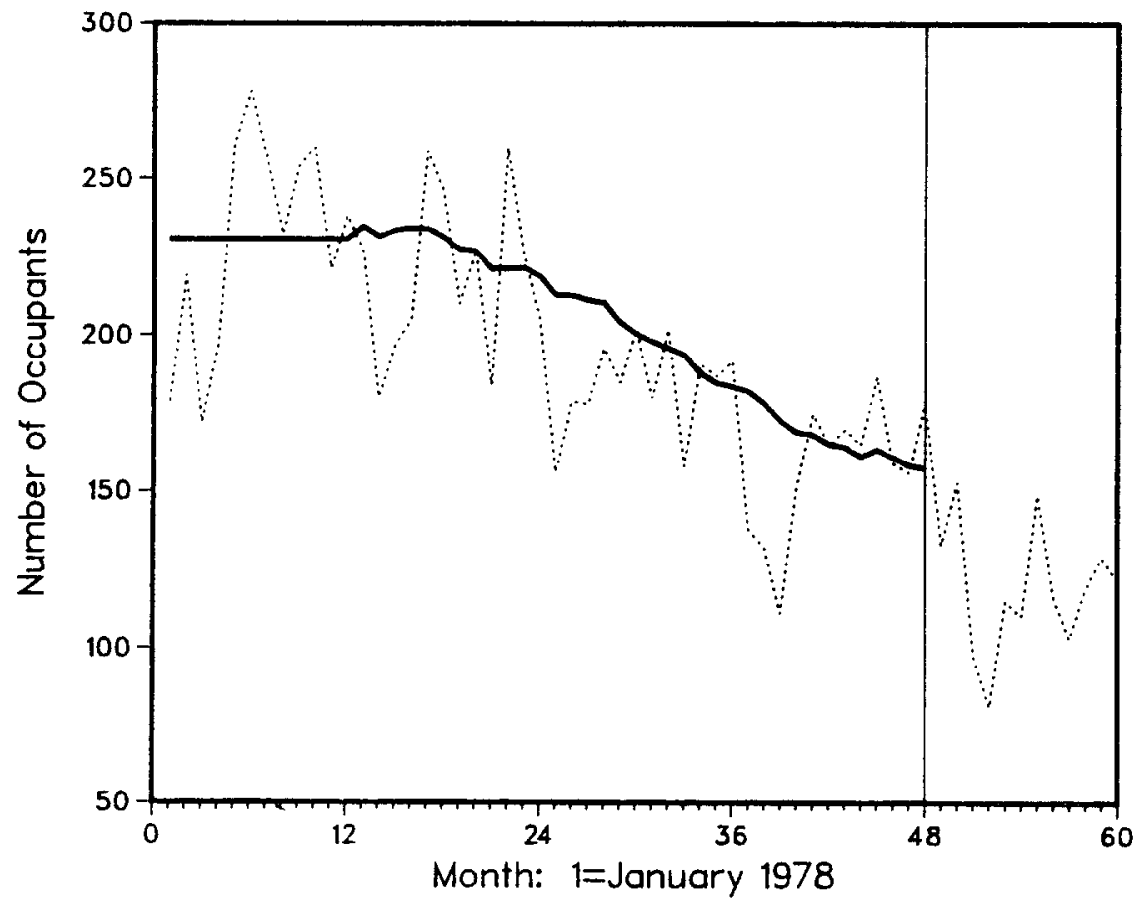

Legend 


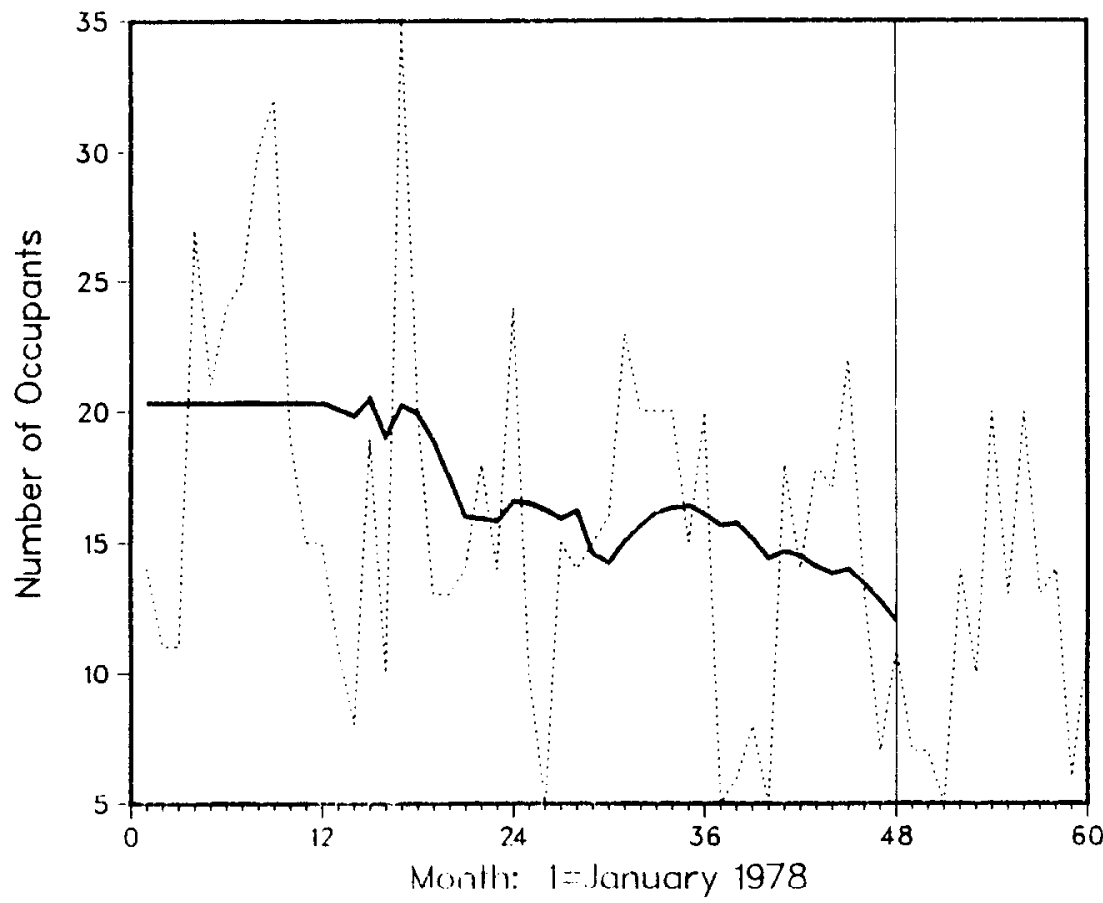

Legend

Severe 0-3

Moving Averago
The traffic Accident Damage (TAD) scale is used by investigating officers to rank the extent of damage to a vehicle on an 8-point ordinal scale (scoring ranges from zero-no damage to 7 -maximum damage). The TAD scale was recalculated into three categories to ensure adequate numbers of cases for analysis. Low damage was TAD scores zero and 1 , medium damage TAD 2 and 3 , and high damage TAD 4 through 7 . The mandatory child restraint law was associated with a $41 \%$ reduction in childhood injuries in low-damage crashes (Figure 3), a $20 \%$ reduction in medium-damage crashes (Figure 4 ), and a $12 \%$ reduction in high-damage crashes (Figure 5). These results confirm the proposition that the child restraint law was most effective in increasing restraint use among those at lower levels of risk for serious injury and least effective among those most at risk for serious injury. Nevertheless, the child restraint law was associated with significant reductions in childhood injuries even among presumably high-risk drivers involved in severe crashes. Furthermore, many injuries to children oc- cur in crashes that involve low or moderate levels of vehicle damage; the child restraint law dramatically reduced injuries in such crashes.

Finally, effects of the child restraint law on injuries among children were examined for various seating positions. There are two dimensions of the new law and associated publicity that may influence seating position of children in automobiles. First, the law states that a child age 1 through 3 must be restrained in an approved child restraint device if riding in the front seat, but use of an adult lap belt is legally adequate in the rear seat. (Infants under age 1 must be in a child restraint device in all seating positions.) Second, publicity and education efforts surrounding the law informed drivers that the safest place for children is in the rear seat.

Time-series analyses were conducted for childhood injuries in three categories of seating position: (a) front seat, (b) rear seat, and (c) other positions (primarily in the cargo area). After controlling for the downward trend during the baseline period, injuries 


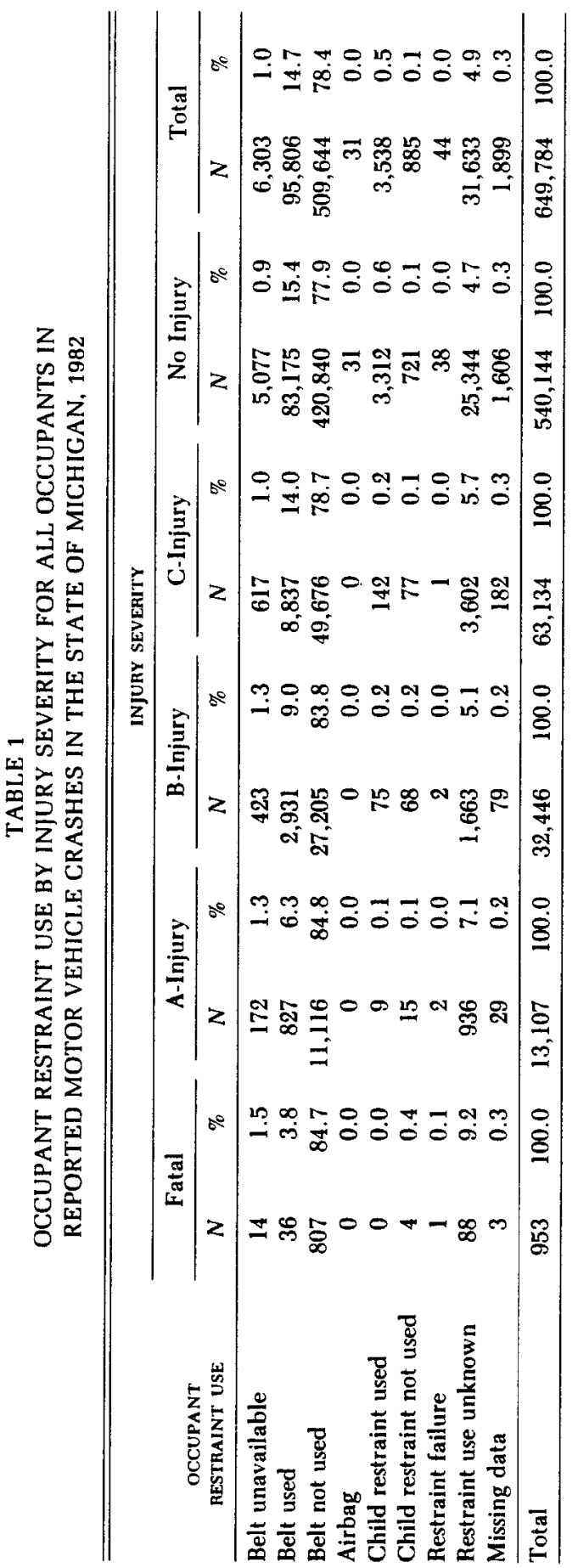


FIGURE 3

MICHIGAN INJURED OCCUPANTS AGE 0 TO 3 IN LOW DAMAGE VEHICLES

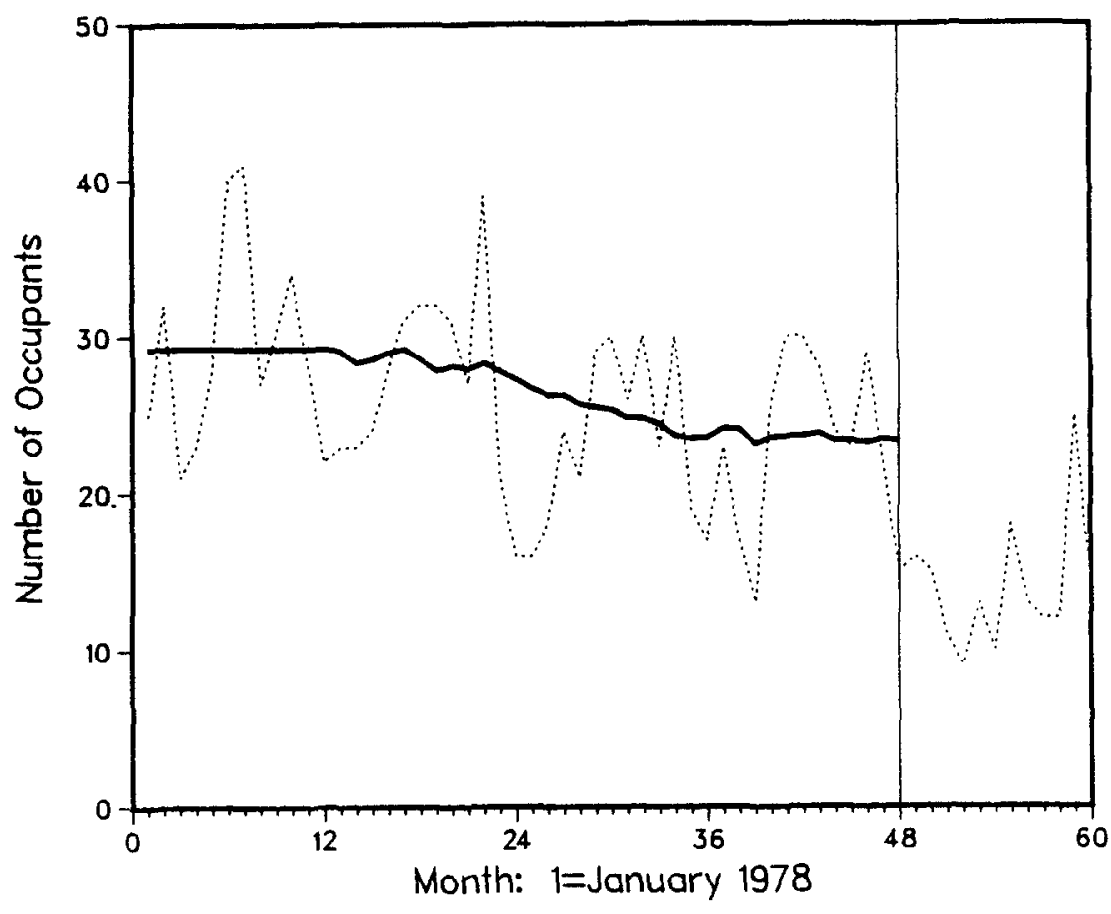

Legend

Low Damage 0-3

Moving Average

FIGURE 4

MICHIGAN INJURED OCCUPANTS AGE 0 TO 3 IN MEDIUM DAMAGE VEHICLES

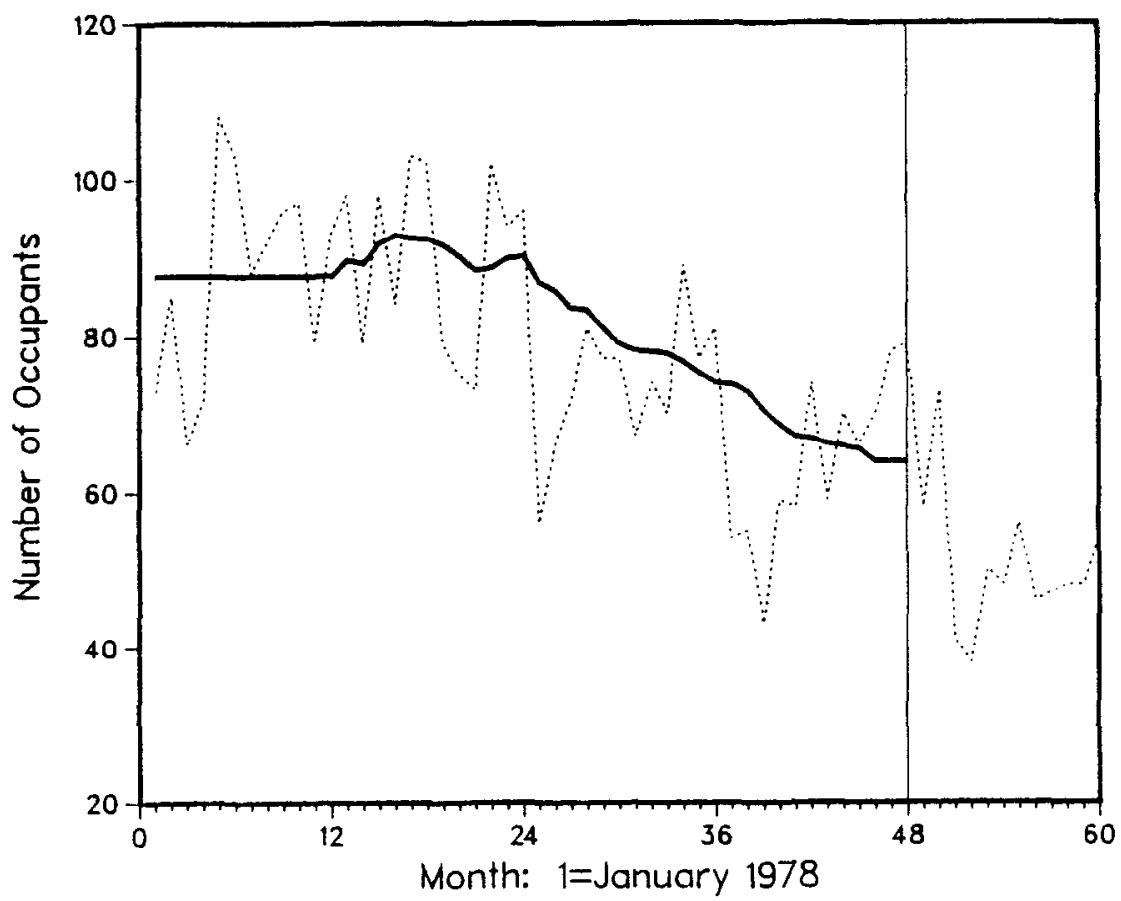

Legend

Hedlem Pomage 0-3

Moving Averore. 


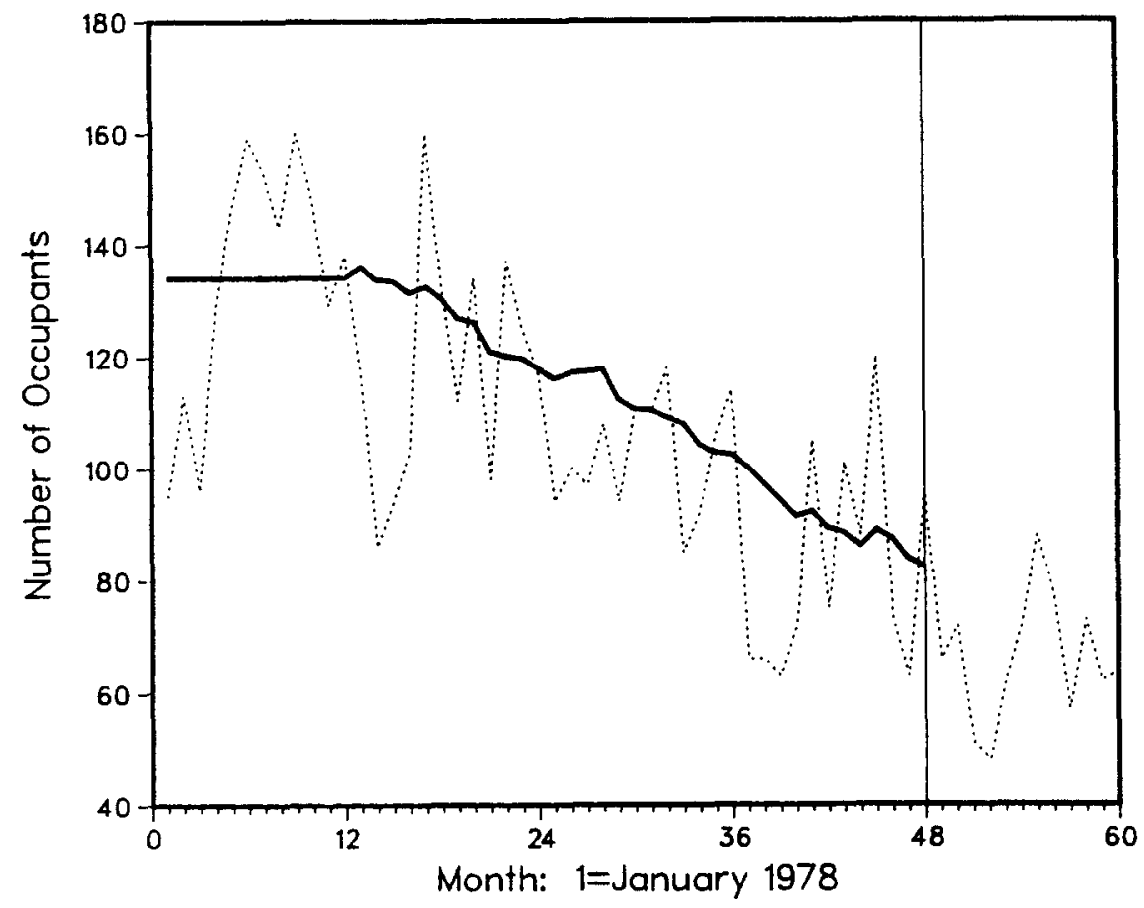

Legend

High Domage 0-3 Moving Averoge among children riding in front seats decreased $28 \%$ when the child restraint law took effect (Figure 6). In contrast, children riding in rear seats experienced no change in injuries (Figure 7). The substantial decrease in front-seat injuries is probably due to a decrease in the number of young children riding in the front seat and an increase in the proportion of those riding in the front seat that are restrained. No net change in the number of children injured in the rear seat is probably the result of two effects. First, some children who before the law rode in the front seat may have been moved to the rear seat. Second, the increased number of children riding in the rear seat did not lead to increased rear-seat injuries because a higher proportion were restrained after the law.

It appears that the number of children riding in positions other than front or rear seats (i.e., cargo areas) declined substantially after implementation of the child restraint law. Injuries among children riding in cargo areas decreased $45 \%$ immediately after the law took effect (Figure 8). Thus, in addition to reducing childhood injuries by increasing restraint use, the law apparently moved children riding in automobiles from the more vulnerable front-seat and cargo-area positions to the safer rear-seat position. This effect, along with increased restraint use, presumably contributed to the overall injury reductions associated with implementation of the child restraint law.

In summary, the effect of the law was primarily a $22 \%$ reduction in moderate childhood injuries. Analyses of severe injuries (a smaller number of cases than moderate injuries) revealed no statistically significant change after controlling for a downward trend over the baseline 1978-1981 period. Analyses of crashes with varying levels of vehicle damage confirmed that the law had its smallest effect among those most at risk for severe injury.

\section{DISCUSSION}

Wagenaar (1984) found that the overall effect of Michigan's child restraint law was a $17 \%$ injury reduction among children age 1 through 3 and a $50 \%$ reduction among in- 
FIGURE 6

MICHIGAN FRONT SEAT INJURED OCCUPANTS AGE 0 TO 3

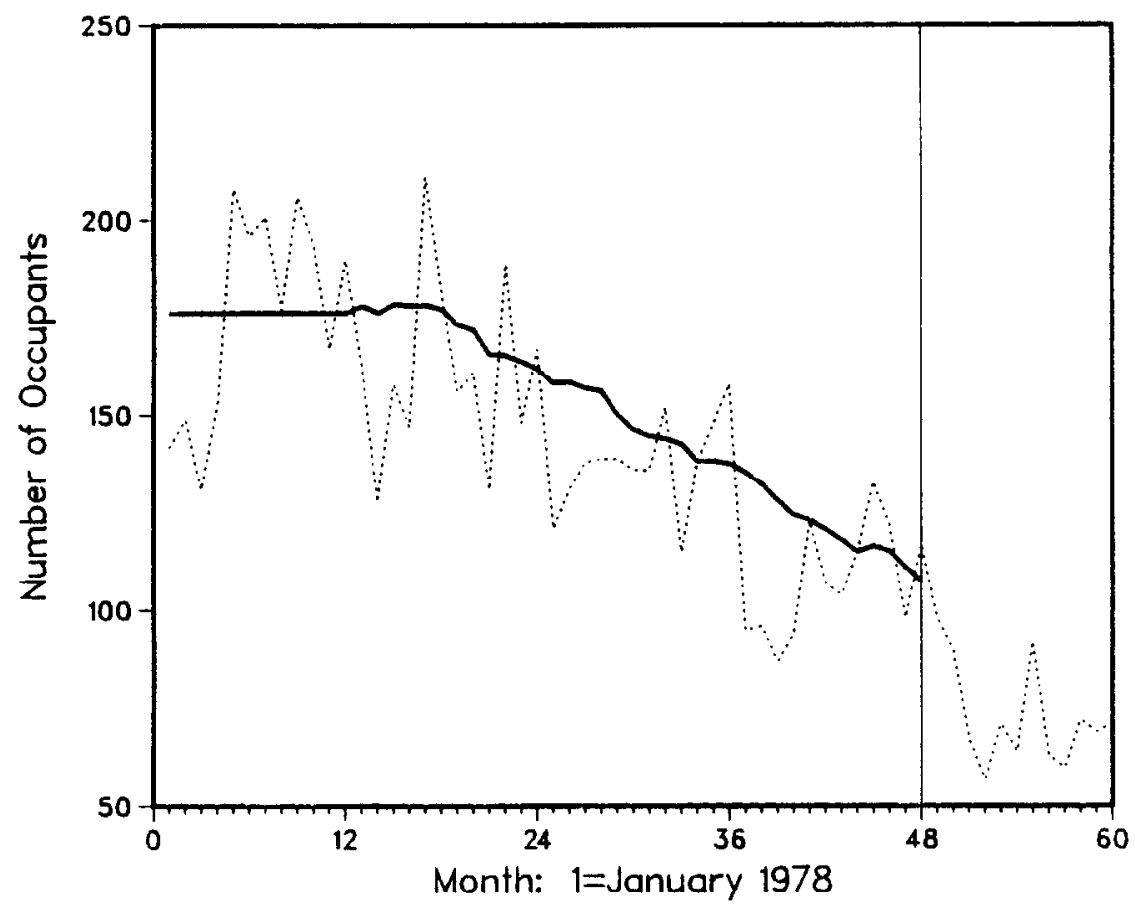

Legend

Front $0-3$

Moving Averoge

FIGURE 7

MICHIGAN REAR SEAT INJURED OCCUPANTS AGE 0 TO 3

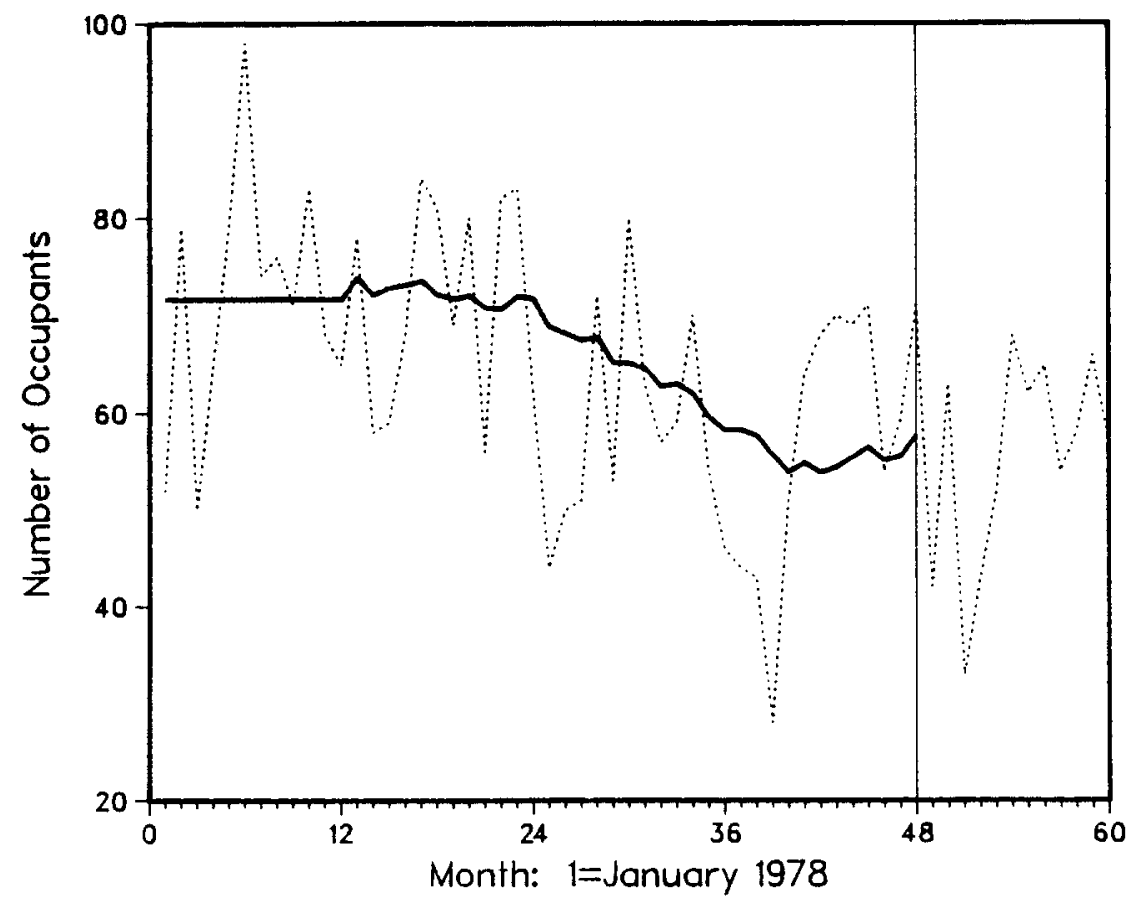

Legend

Rear 0-3

Moving Averoge 


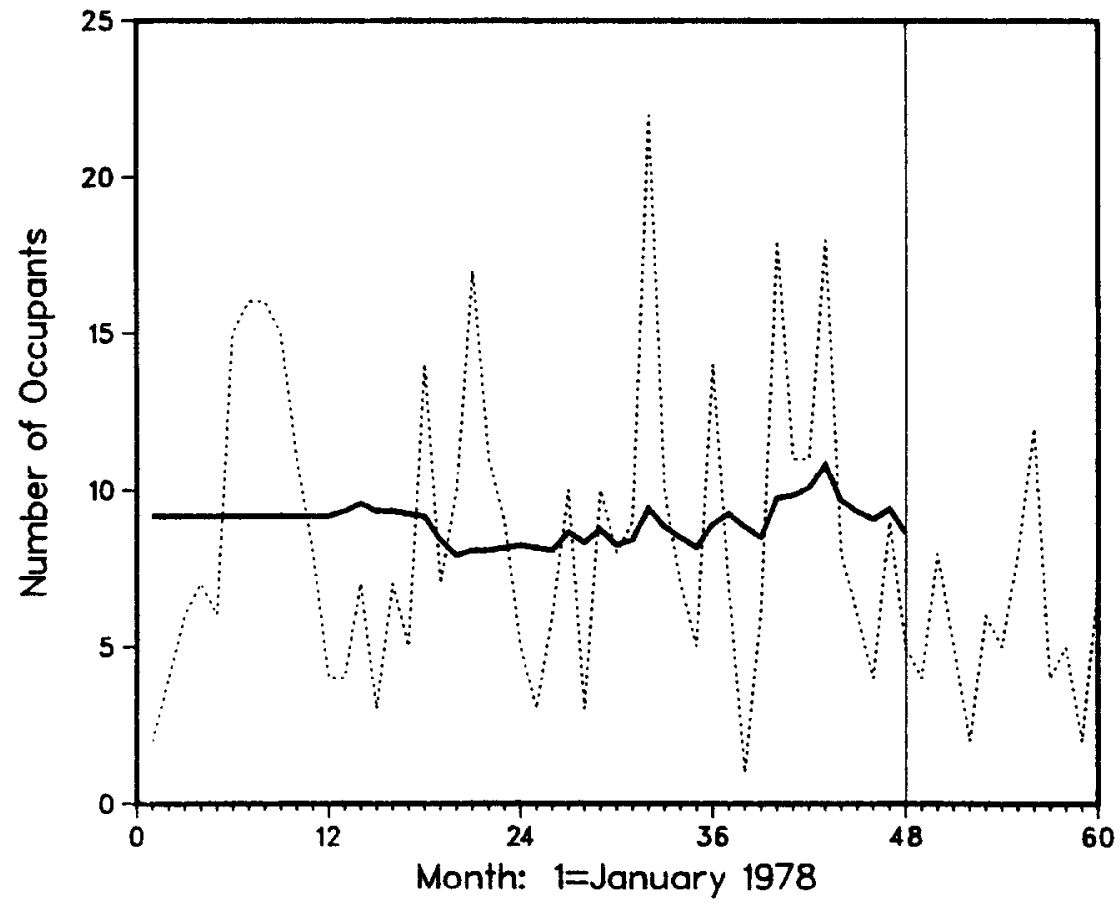

Legend

Corgo $0-3$ Moving Avaroge fants under 1. Hearne (1981) has argued that a mandatory restraint law must increase use to over $80 \%$ before reaching those most at risk for injury; only then will a law significantly reduce the total number of injuries. Results of the Michigan studies, however, indicate that a much smaller increase in restraint use significantly reduces casualties. An increase in restraint use from 12 to $36 \%$ among crash-involved children resulted in a $17 \%$ decline in injuries (Wagenaar, 1984). The results reported here clarify the mechanism for such injury reductions. In addition to the significant increase in restraint use, the law and associated PI\&E programs also apparently reduced childhood injuries by increasing the proportion of children riding in the safer rear-seat position.

The present study also found that the injury reductions associated with the child restraint law are primarily due to reduced injuries among those in low- and moderate-damage crashes. Given that those most influenced by the law are at lower risk of injury, a further increase in use of $24 \%$ is likely to result in more than a $17 \%$ decline in injuries. The potential benefits in reduced injuries of further increases in restraint use are dramatic. However, each marginal increase in the proportion of the population using restraints is likely to be more difficult to achieve. What can be done to continue and enhance the success thus far?

First, public information and education efforts should continue. Results reported by Wagenaar (1984) indicate that Michigan's PI\&E efforts apparently had some effect in increasing child restraint use even before the law took effect. As noted earlier, effects attributed to the law in this discussion really refer to the combined effect of the law and PI\&E efforts. Other research has also found that comprehensive PI\&E programs can significantly affect motorists' awareness of the need for restraints (Philpot, Heathington, Sontag, Culler, \& Cunningham, 1980). Because significant changes in restraint-using behavior are difficult to achieve with $P I \& E$ efforts alone, perhaps the focus of these efforts should be to build public support for 
mandatory restraint use laws and automatic restraint systems, two ways of achieving significant increases in occupant protection.

Second, enforcement of current child restraint laws should be strengthened. Available evidence indicates that major enforcement efforts can increase restraint use. For example, Roberts (1981) noted that child restraint use in Tennessee "doubled" after a stepped-up enforcement program was initiated (although no data were provided to substantiate the claim). Jonah, Dawson, and Smith (1982) compared two Ontario cities, one of which implemented a selective belt-use enforcement program (including publicity about the increased enforcement). Belt use increased from $58 \%$ before to $80 \%$ during the program, declining to $70 \% 6$ months after program termination. Resource limitations constrain the extent to which child restraint laws can be enforced. Nevertheless, a moderate level of enforcement is needed to persuade motorists that the state is serious about protecting children riding in motor vehicles.

Third, the legal system should be used in other ways to encourage use of restraints. For example, failure to use an available occupant restraint device might be considered contributory negligence. As a result, compensation for crash-related damages awarded in civil suits would be reduced if the plaintiff had not used a restraint device. Although evidence concerning the effectiveness of such a "seatbelt defense" in increasing belt use is limited, Mackay (1981) notes that the seat belt defense is routine in Great Britain, and Green and Sharpe (1981) note that its use is growing in Canada.

Finally, the most obvious recommendation emerging from this study is that child restraint laws should be extended to motor vehicle occupants of all ages. Werber (1980) and Wanebo (1982) reviewed the legal issues surrounding mandatory restraint use laws and concluded that such laws are clearly constitutional. Fuchs (1978) argued that mandatory belt use laws are the best way to reduce highway casualties because they reallocate responsibility for preventing serious injury to those best able to so do. Based on results of the studies of the Michigan child restraint law, a mandatory adult restraint law is likely to significantly reduce crash-related injuries, even if the high rates of restraint use (i.e., $80 \%$ or over) observed in other countries with mandatory laws are not achieved. A more modest increase in use (i.e., to about $50 \%$ ) is still likely to have a significant effect in reducing injuries. The potential benefits of an $80 \%$ or more use rate are immense, however; such high levels of use should continue to be the goal.

\section{REFERENCES}

Andary J. J., Flora, J. D., Huelke, D. F., \& O’Day, J. (1981). Estimates of direct costs to the state resulting from traffic accidents. Ann Arbor: The University of Michigan Highway Safety Research Institute.

Barancik, J. I., Chatterjee, B. F., Greese, Y. C., Michengi, E. M., \& Fife, D. (1983). Northeastern Ohio trauma study. American Journal of Public Health, 73 (7), 746-751.

Fuchs, J. R. (1978). Reallocating the risk of loss in automobile accidents by means of mandatory seat belt use legislation. Southern California Law Review, 52, 91158.

Green, R. N., \& Sharpe, G. S. (1981). Restraint systems and the law. In R. N. Green \& E. Petrucelli (Eds.), The human collision: Proceedings of the International Symposium on Occupant Restraint (pp. 87-97). Morton Grove, IL: American Association for Automotive Medicine.

Hearne, R. (1981). The initial impact of the safety belt legislation in Ireland. Dublin, Ireland: An Foras Forbartha, The National Institute for Physical Planning and Construction Research.

Jonah, B. A., Dawson, N. E., Smith, G. A. (1982). Effects of a selective traffic enforcement program on seat belt usage. Journal of Applied Psychology, 67(1), 8996.

Kaufman, G. \& Bilge, B. (1982). Effects of automobile accidents upon American families (DOT No. HS 806 315). St. Clair Shores, Michigan; Bilge-Kaufman Research.

MacKay, G. M. (1981). Seat belts in Europe - Their use and performance in collisions. In R. N. Green and E. Petrucelli (Eds.), The human collision: Proceedings of the International Symposium on Occupant Restraint (pp. 39-51). Morton Grove, IL: American Association for Automotive Medicine.

McGinley Marketing Research, Inc. (1982). Michigan seat belts. Upper Darby, PA: Author.

New York State Department of Motor Vehicles. (1983, January). Seat belt requirement for learner's permit holders. Department of Motor Vehicles News.

O'Day, J., \& Filkins, L. D. (1983). Attitudes toward wearing belts: A survey of Michigan drivers. The UMTRI Research Review, 14, 1-8.

O'Day, J., \& Wolfe, A. C. (1984). Seat belt observations in Michigan: September/October 1983. Ann Arbor: The University of Michigan Transportation Research Institute.

Office of Highway Safety Planning. (1981). Public Act 117 Comprehensive Plan. Lansing: Michigan Depart- 
ment of State Police.

Philpot, J. W., Heathington, K. W., Sontag, D. B., Culler, C. J., \& Cunningham, J. L. (1980). Use of telephone surveys to determine awareness of Tennessee's child passenger protection law. Knoxville, TN: Transportation Center, University of Tennessee.

Roberts, G. (1981). Child passenger protection: The Tennessee enforcement strategy. In R. N. Green and E. Petrucelli (Eds.), The human collision: Proceedings of the International Symposium on Occupant Re. straint (pp. 189-200). Morton Grove, IL: American Association for Automotive Medicine.

Rubin, L. R. (1982). Children in automobile accidents: The effects on the family (DOT No. HS 806 316). Washington, DC: U.S. Department of Transportation, National Highway Traffic Safety Administration.
Verway, D. I. (1982). Michigan statistical abstract (16th ed.). Detroit, MI: Wayne State University, School of Business Administration.

Wagenaar, A. C. (1984, October). Effectiveness of mandatory child restraint laws. In 28th Annual Proceedings of the American Association for Automotive Medicine, Denver, CO.

Wanebo, L. (1982). Child safety in automobiles: Mandatory restraint-use laws. University of Colorado Law Review, 52, 125-150.

Warner, E. E. (1983). Bags, buckles, and belts: The debate over mandatory passive restraints in automobiles. Journal of Health Politics, Policy, and Law, $8(1), 44-75$.

Werber, S. J. (1980). A multi-disciplinary approach to seat belt issues. Cleveland State Law Review, 29, 2217-2277. 